\title{
Scale and Scope Economies in Chinese Life Insurance Industry
}

\author{
Jing Lu \\ Insurance School, \\ Central University of Finance and Economics, \\ Beijing 100081
}

\begin{abstract}
Using the Translog model and the data of all life insurance companies in China from 2012 to 2015, this paper analyzes the scale effect and scope effect in China's life insurance market. In this paper, the premium income of various types of insurance as the output of the company, rent and wages as input elements, Commission and commission expenditure, business and management fees as the operating costs of insurance companies. The results show that both large $\&$ medium-sized life insurance companies have economies of scale, and the scale effect of small life insurance companies is significantly stronger than that of large $\&$ medium-sized life insurance companies. In terms of scope effect, it is difficult to draw a unified conclusion from the 2012-2015 year's model results. According to the results of the model in 2015, ordinary life insurance and health insurance, health insurance and other insurance have costcomplementary effects
\end{abstract}

\section{INTRODUCTION}

In recent years, China's insurance market has made great progress, and industry supervision has also undergone great changes. The "Several Opinions of the State Council on Accelerating the Development of Modern Insurance Service Industry" promulgated in August 2014 emphasizes that the market plays a decisive role in resource allocation. The resource allocation function of the market is gradually playing a role. In the life insurance market, market-oriented reform measures for various types of insurance are actively carried out. The general, universal and dividend-paying life insurance rate reforms were completed in August 2013, February 2015 and October 2015, respectively, which marked the establishment of a mechanism for the formation of life insurance premium rates in China. Under the background of such marketization, the research on the market structure of China's life insurance industry has urgency and significant practical significance. If the life insurance industry has a certain scale effect or range effect, compared with large-scale and diversified large-scale life insurance companies, small and medium-sized life insurance companies will have competitive disadvantages due to their small scale and usually single products. Even in the long run, it is difficult to sustain. At the same time, there are serious barriers to entry for new life insurance companies entering the market. As a result, China's life insurance market may gradually lose its benign competition mechanism and eventually form an oligopoly.

Therefore, whether there is scale effect and scope effect in China's insurance industry, whether insurance companies expand their business scope and provide diversified insurance products is more conducive to insurance companies to improve the efficiency of resource allocation and reduce the average operating costs. These problems have gradually become the topics of concern to regulators, academia, and the insurance industry. At the same time, the research on the industrial structure of the life insurance market is conducive to better understanding of the market. On one hand, it provides ideas for the industry regulatory authorities to formulate 
regulatory policies and measures. On the other hand, it also provides suggestions for the development of business strategies for life insurance companies of all sizes.

Foreign academic circles have studied the scale effect and scope effect of the insurance industry, but there is still a lack of comparative system and mature judgment on whether the insurance industry has scale effect and scope effect. In the existing research on foreign mature insurance market, the research conclusions obtained are generally that the insurance industry has certain scale effect and range effect. Most of the domestic research objects on this issue are general industrial enterprises or commercial banks, and there are very few studies on the scale effect and scope effect of the insurance industry. This paper attempts to draw some conclusions that are conducive to the further sustainable and healthy development of the life insurance industry through the modeling and analysis of China's life insurance industry data. The second part of this paper analyzes the related concepts and basic theories of industrial economics and their application in the life insurance industry; the third part describes the data source and regression process of this paper; the fourth part carries on the regression results; the fifth part is the full text to sum up.

\section{Definition of scale effect and range effect}

\section{RELATED CONCEPTS}

For a company that produces only a single product, the scale effect refers to the phenomenon that a company's average cost decreases as the total output increases. Expressed by the formula, the scale effect when producing $y$ is

$$
S=C(\mathrm{y}) / y C(y)=A C(y) / C(y)
$$

That is, the average cost / marginal cost. If $S$ is greater than 1 , the scale returns are incremented; If $S$ is equal to 1 , the scale returns are unchanged; If $S$ is less than 1 , the scale returns are decremented.

For a company with multiple outputs, the formula for the overall scale effect is

$$
S=C(\mathrm{y}) /{ }_{i=1}^{n} y_{i} C_{i}(y)
$$

In the formula, $C_{i}(y)=C(y) /\left(y_{i}\right)$

When $\mathrm{S}$ is greater than 1 , equal to 1 , or less than 1 , the overall scale effect is increasing, invariant, or decreasing.

At the same time, when a company chooses to carry out multiple output activities simultaneously, the overall cost of reaching a certain output level may be lower than the sum of the costs of independently outputting between different companies. It's the range effect. The range effect was originally proposed by the two American economists Panzer and Willing in 1975. The range effect comes from many aspects of company management, production equipment and other savings. In the case where the output level is vector $y$, the formula for the range effect relative to the output set $\mathrm{T}$ is expressed as follows:

$$
S C_{\mathrm{T}}(y)=\left[C\left(y_{T}\right)+C\left(y_{N T}\right) \quad C(y)\right] / C(y)
$$




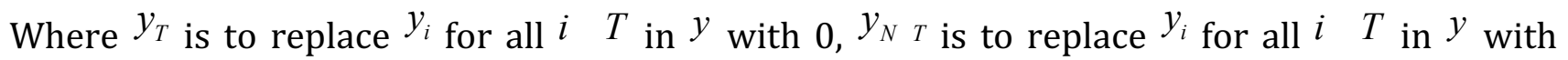
0 . In the formula, the range effect reflects the increase in production costs when the output level $\mathrm{y}$ is decomposed into $\mathrm{T}$ and $\mathrm{N}-\mathrm{T}$.

\section{China's life insurance industry}

According to the 2012-2015 China Insurance Yearbook, the number of life insurance companies in China from 2012 to 2015 was 63, 66, 66 and 78 respectively. These life insurance companies are all joint-stock companies. The first mutual insurance company of China's life insurance industry, Trust Mutual Life Insurance, was formally approved by the China Insurance Regulatory Commission in April 2016. From the perspective of premium scale, China's life insurance industry has a high market concentration. The four largest companies (China Life, Ping An Life, China Pacific Life, New China Life Insurance) account for more than $50 \%$ of China's life insurance market. According to the public data of 2015, from the perspective of the original insurance premium income, ordinary life insurance accounts for $42.15 \%$ of China's life insurance market, and participating insurance and health insurance account for $40.77 \%$ and $13.71 \%$ respectively. Other insurance types (investment-type insurance and accident insurance) account for 3.4\%. Ordinary life insurance still occupies the most important position, followed by the proportion of ordinary life insurance is participating life insurance, while health insurance and other insurance only accounted for 17.1\%. Compared with the property insurance industry's 2014 premium income data, the auto insurance market accounted for $73.2 \%$ of China's property insurance market, property insurance and liability insurance accounted for 5.7\% and 3.4\% respectively, and other insurance types accounted for $17.7 \%$, and auto insurance occupied more than $70 \%$ of the market far exceeds other types of insurance. It can be seen from Table 1 that the proportion of ordinary life insurance has increased significantly year by year, and participating life insurance has shown a trend of drastically decreasing year by year. Among them, the proportion of ordinary life insurance premiums in 2015 exceeded the proportion of participating insurance and health insurance for the first time. There is a slight increase in the trend, and the proportion of investment-type life insurance products and accident insurance is relatively small.

Table 1 Proportion of premium income for each type of life insurance in 2012-2015

\begin{tabular}{|l|c|c|c|c|c|}
\hline Year/Type & $\begin{array}{c}\text { Ordinary } \\
\text { life }\end{array}$ & $\begin{array}{c}\text { participating } \\
\text { life }\end{array}$ & $\begin{array}{c}\text { Investment-type(Investment- } \\
\text { linked, universal life) }\end{array}$ & Accident & Health \\
\hline 2012 & $8.83 \%$ & $79.46 \%$ & $1.04 \%$ & $2.66 \%$ & $8.01 \%$ \\
\hline 2013 & $10.43 \%$ & $76.28 \%$ & $0.89 \%$ & $2.95 \%$ & $9.46 \%$ \\
\hline 2014 & $33.23 \%$ & $51.53 \%$ & $0.97 \%$ & $2.96 \%$ & $11.32 \%$ \\
\hline 2015 & $42.15 \%$ & $40.77 \%$ & $0.64 \%$ & $2.74 \%$ & $13.71 \%$ \\
\hline
\end{tabular}

Data Source: China Insurance Yearbook 2013-2016

Table 2 Proportion of premium income for each type of property $\&$ casualty insurance in 2012 2015

\begin{tabular}{|l|c|c|c|c|}
\hline Year/Type & $\begin{array}{c}\text { Property(Corporate } \\
\text { property,family } \\
\text { property) }\end{array}$ & Auto & Liability & Other \\
\hline 2012 & $6.94 \%$ & $72.61 \%$ & $3.28 \%$ & $17.18 \%$ \\
\hline 2013 & $7.05 \%$ & $80.37 \%$ & $3.66 \%$ & $8.93 \%$ \\
\hline 2014 & $5.73 \%$ & $73.19 \%$ & $3.39 \%$ & $17.70 \%$ \\
\hline
\end{tabular}

Data Source: China Insurance Yearbook 2013-2016 
Compared with developed foreign markets, the insurance types of various companies in China's insurance market are relatively close., and usually operate life insurance, health insurance and accident insurance. Relatively speaking, the development of the insurance industry in developed countries is relatively mature and the market segmentation is more detailed. There are companies operating only a single type of insurance, or only one type of insurance in a certain area is designed and sold. . Of course, the various insurance needs in foreign mature insurance markets have been deeply explored. China's insurance industry can fully learn from this experience, deeply explore various insurance needs, and design products and services that better meet market demand.

\section{Industrial economics of the life insurance industry}

Research scholars at home and abroad have studied the scale effect and scope effect of financial markets, and usually put the scope effect and scale effect together for research. Foreign scholars use Cobb-Douglas cost function (Kellner \& Mathewson, 1983), Generalized Translog Cost Function (GTCF) (Grace \& Timme, 1992), Transcendental Log Cost Function (Translog) Cost Function (TCF) (Meador, Ryan \& Schellhom, 1992), and the Cost Function (Berger, 1999) model are used to fit the cost function of the insurance company, and the research conclusions are also different.

Chinese scholars have also conducted some research on the scale effect and scope effect of the insurance industry. Huang Wei (2007) analyzes the scope economies of several insurance institutions one by one based on the generalized transcendental logarithm cost function. The overall range of economic effects of the property insurance industry is not obvious, but the life insurance market presents an obvious range of economic phenomena. $\mathrm{Hu}$ and $\mathrm{Su}$ (2013) also used the generalized transcendental cost function to estimate the range economic function of China's major property insurance companies one by one. The results show that China's property insurance market has both a range of economies and a range of economics. Wang and Lu (2016) used the Translog model to simultaneously analyze the scale effect and range effect in China's property and casualty insurance market. The results of the model show that when the income of the property insurance company is measured by the premium income, the large \& medium-sized property and casualty insurance companies with large asset scales are not economically large, while the small property insurance companies are economies of scale; the output of the property insurance companies is measured by insurance claims. At the time, in addition to the results of large \& medium-sized property and casualty insurance companies in individual years, the sample data of various property and casualty insurance companies showed economies of scale. However, the range effect did not yield a consistent result.

\section{Cost model}

\section{MODEL ANALYSIS}

This paper uses Translog model to analyze the scale effect in life insurance market. In the related research on the cost structure of different industries, the Translog model has been widely used. The advantage of the Translog model is the ability to measure multiple outputs of the company, thereby avoiding unreasonable assumptions about the same factor price, the same output structure, product homogeneity, and the average cost of monotonous products in a single output model. The Translog model only requires a dual relationship between the cost and the transformation function, and there is no limit on the first and second derivatives. Compared to other flexible functions, there are fewer parameters to estimate in the Translog model. The disadvantage of the model is that when the output level is zero, the cost must be zero, so that fixed costs cannot be measured. Overall, the Translog model has become the primary model used by the multi-output cost analysis study due to the flexibility of the model. 
The Translog model used in this paper is essentially Taylor expansion on the quantity of outputs and the price of elements. The specific model form is as follows:

$$
\begin{aligned}
& \ln C={ }_{0}+{ }_{i=1}^{n} i \ln y_{i}+\quad{ }_{j=1}^{m} \quad j \ln w_{j}+\frac{1}{2} \quad \begin{array}{lll}
n & n_{i} &
\end{array} \quad \ln y_{i} \ln y_{k}
\end{aligned}
$$

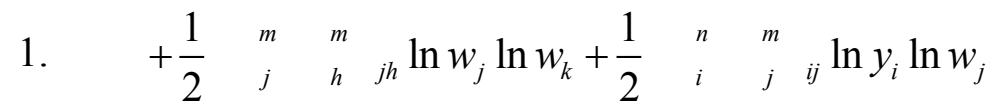

Where $\mathrm{C}$ is the total cost, $\mathrm{y}$ is the output, and $\mathrm{w}$ is the factor price.

As a cost model, (1) is linearly homogeneous for all factor prices. It requires:

$$
{ }_{j=1}^{m} \quad j=1 \quad{ }_{j}^{m} \quad \text { ij }=0 \quad{ }_{j}^{m} \quad{ }^{j h}=0
$$

In the model, $y_{1}, y_{2}, y_{3}, y_{4}$ represent premium income for general life insurance, participating insurance, health insurance, and other types of insurance (including universal insurance, investment-linked insurance, and accident insurance). $w_{1}, w_{2}$ represent wage cost and rental cost (unit rental price), respectively.

\section{Scale economy and scope economy}

Based on the estimation of Translog model, this paper can calculate the economies of scale and scope economy in the life insurance industry. The calculations follow the relevant definitions in Panzar and Willig (1977) and Baumol, Panzar and Willig (1982), and the estimation methods by Murray and White (1983) and Kim (1987).

Panzar and Willig (1977) demonstrate that the overall scale effect of multi-output firms is as follows:

$$
S L=C(Y, W) / \quad{ }_{i}^{n} y_{i} M C_{i}=1 / \quad{ }_{i}^{n} \frac{\ln C}{\ln y_{i}}=1 / \quad{ }_{i}^{n} \quad{ }_{i}
$$

In which, MC is the marginal cost of the i-th output and ${ }^{i}$ is the cost elasticity. From the Translog model, the expression of $i$ that can be obtained is

$$
{ }_{i}={ }_{i}+{ }_{k}^{n} i k \ln y_{k}+{ }_{j}^{m}{ }_{i j} \ln w_{j}
$$

According to Suret (1991), in the point estimation, when $y_{k}=w_{j}=1$, the overall scale effect becomes:

$$
S L=\left(\begin{array}{lll} 
& & \\
& i
\end{array}\right)^{-1}
$$

This simplification requires standardization of the data prior to estimating the model, which is used by Muray and White and Kim.

Panzar and Willig (1977) point out that in the multi-output cost structure, the condition of range effect is:

$$
{ }^{2} C / y_{i} y_{j}<0, i \quad j
$$

The approximate test of this condition is:

$$
{ }_{i \quad k}+{ }_{i k}<0
$$


A combination of outputs that meets this condition has a cost-complementary effect, enabling a company that produces the combination to have a cost advantage over a company that only produces one product.

\section{Output}

\section{DATA SOURCE ANALYSIS AND REGRESSION PROCESS}

All research on insurance costs has encountered difficulties associated with the definition of outputs and the appropriate level of output summation. For example, Geehan (1986) has a useful discussion of the issues involved and compared major studies using different output measures. In this study, output definitions based on premium and annuity considerations were used. This is consistent with the methods used by many authors (for example, Joskow, 1973, Blair, Jackson and Vogel, 1975 and Weiss, 1986). In addition, the dollar value of the investment is also defined as output. Due to the long-term nature of life insurance products, the life insurance company's business is divided into two parts: underwriting business and investment business. Among them, the investment business has become the main business of most life insurance companies. Therefore, it is appropriate and necessary for the life insurance company to consider investment as an output consideration, which is absolutely different from property insurance companies. This is also consistent with previous cost studies by financial intermediaries (eg, Gilligan, Smirlock, and Marshall, 1984, Mester, 1987).

Therefore, this article refers to the setting in Grace M F \& Timme S G. (1992), the premium of each product line as an output. Specifically, according to the data in the insurance yearbook, the premium income of ordinary life insurance, participating insurance, health insurance and other insurance types is taken as the output of the life insurance company.

\section{Factor price}

The production factors of an enterprise mainly include labor, capital, land and entrepreneurship. In the analysis of the factors of the life insurance industry, it is assumed that the price of the capital factor of the life insurance company is the same, because the enterprises in the same industry generally think that they have the same or relatively close risk categories. According to Miller (1997), even if the financial leverage of each company is different, the cost of funds will not be affected. In the previous article research, the price of this factor of entrepreneurial talent has not been considered, and this model is still used in this paper.

\section{Labor factor price}

The data of the labor factor price is the average wage level of each person's life insurance company. The data source is the China Regional Economic Statistical Yearbook. Since each person's life insurance company opens a company headquarters at the place of registration, it handles the relevant internal management affairs of the company; sets up branches and branches in the business development area to handle the daily business sales of the company. Since the sales expenses of the business are mainly reflected in the accounting items of commissions and commissions, this paper assumes that the wages of the branch companies are smaller than the wages of the headquarters. Therefore, the average salary level of the city where the registration is located is chosen to represent each person. The price of labor factors of insurance companies.

Table 3 shows where each person's life insurance company is registered. China has a vast territory, and the regional economy and local financial development have shown large differences. By observing the registration places of life insurance companies in China, we can see that the distribution of national life insurance companies is mainly concentrated in economically developed areas. For example, there are 46 insurance companies in Beijing, 
Shanghai and Shenzhen, accounting for the total number of life insurance companies. 70\%; In Guangdong Province, in addition to the provincial capital of Guangzhou, insurance companies are also located in the separate cities of Shenzhen.

Table 3 Registration place of each life insurance company (2012)

\begin{tabular}{lclclc}
\hline \multicolumn{2}{l}{ Registration No. of } & \multicolumn{2}{l}{ Registration No. of } & \multicolumn{2}{l}{ Registration No. of } \\
place & company & place & company & place & company \\
\hline Beijing & 23 & Nanjing & 1 & Changsha & 1 \\
Shanghai & 17 & Shenyang & 1 & Wuhan & 1 \\
Shenzhen & 6 & Suzhou & 1 & Chongqing & 1 \\
Tianjin & 3 & Hangzhou & 1 & Xiamen & 1 \\
Dalian & 2 & Chengdu & 1 & Hainan & 1 \\
Guangzhou & 1 & & & &
\end{tabular}

Source of data: official website of each insurance company, collected and collated by the author.

\section{Land element price}

Regardless of whether the life insurance company is owning an office building or renting it, the rent of the office building is listed as the company's expense item in the company's cost assessment (UK Actuary Examination, CA1). Similar to the assumption of labor factor price, this paper assumes that the rental cost of the branch office building is also significantly lower than the rental cost of the headquarters office building, so the average rent level of the Grade A office building in the city where each life insurance company is registered is used. Measure the price of land elements of a life insurance company. The data sources are the real estate market research and analysis reports of various real estate research institutions such as Colliers International, Jones Lang LaSalle, DTZ, and Savills Davis.

\section{Operating cost}

Data on premium income and operating expenses are from the China Insurance Yearbook 2013-2016. This article takes ordinary life insurance, participating insurance and health insurance as the main types of insurance. The premiums of these three types of insurance account for about $90 \%$ of the total market, of which participating account for more than $50 \%$. In the past three years, the proportion of ordinary life insurance has increased year by year, which can be considered as the result of the market-oriented reform of ordinary life insurance.

Except for insurance companies that do not carry out major types of insurance and insurance companies with an operating cost of 0 , all life insurance companies in the Insurance Yearbook are included in the sample group of this article. Figure 2 shows the division criteria and number of large \& medium-sized life insurance companies and small life insurance companies in each year from 2012 to 2015. This article uses the asset size of 20 billion yuan as the standard for large \& medium-sized life insurance companies and small life insurance companies ( 20 billion yuan in 2014, 15 billion yuan in 2013, and 10 billion yuan in 2012). After the division, the sample size of large \& medium-sized life insurance companies and small life insurance companies in each year is basically the same, which is about 33 .

Figure 2 Sample size and criteria of 2 groups in each year

\begin{tabular}{|c|c|c|c|c|}
\hline Year & Large\& Medium & Small & Total & Criteria(yuan) \\
\hline 2012 & 33 & 30 & 63 & 100 billion \\
\hline 2013 & 33 & 33 & 66 & 150 billion \\
\hline 2014 & 33 & 33 & 66 & 200 billion \\
\hline 2015 & 37 & 34 & 71 & 200 billion \\
\hline
\end{tabular}


According to the setting in Grace M F \& Timme S G. (1992), the company's operating costs include labor, capital and miscellaneous expenses. Among them, labor costs include fees and commissions, wages, etc. Capital costs are the rental cost of buildings and equipment and the depreciation of furniture and equipment. Miscellaneous expenses include legal and accounting fees, travel expenses, advertising fees and other fees. After searching and comparing, we believe that the fee and commission expenses, business and management fees in the income statement of China's insurance companies fully include these expenses. Therefore, we choose commission expenses, business and management fees as operating costs.

\section{Regression process}

In the Translog model, each variable is linear, so the model is estimated using the OLS estimation method. In this paper, the STATA software is used to perform regression analysis on the overall sample data and grouped sample data for each year of 2012-2015, and multicollinearity test and heteroscedasticity test are performed. To solve the multicollinearity problem of the data, the variables in the product term of the model are normalized. After estimating the Translog model, the scale effect of each annual sample group is calculated according to formula (4), and then according to condition (6), it is judged whether there is a range effect between different business lines of the life insurance company.

\section{MODEL RESULTS AND ANALYSIS}

As the Translog model has many regression coefficients and the regression results are long, the results of the scale effect and range effect are only shown in the paper. The model results are shown in Table 4-7.

In terms of scale effect, the results of the 2012-2015 model are consistent, and large \& medium-sized life insurance companies and small life insurance companies all have economies of scale. This result shows that regardless of the size of the life insurance company, the increase in premiums will inevitably be accompanied by an increase in costs. As long as life insurance companies want to expand their premium income and increase their market share, they must bear the reality of increased insurance claims, fees and commissions, business and management fees. Life insurance companies lack effective cost control, and even large \& medium-sized life insurance companies are still unable to effectively control costs while expanding their premiums.

At the same time, the scale effect of small life insurance companies is significantly stronger than that of large \& medium-sized life insurance companies. This shows that small life insurance companies want to expand the premium scale and need to pay higher costs than large \& medium-sized life insurance companies that expand the same premium scale. This phenomenon makes small life insurance companies in a disadvantage position in the competition.

In terms of range effects, it is difficult to draw a unified conclusion from the 2012-2015 model results. From the results of the 2015 model, ordinary life insurance and health insurance, health insurance and other insurance have the effect of complementary costs. Therefore, the life insurance company also carries out general insurance and health insurance at the same time in the premium competition. For small life insurance companies, the simultaneous development of participating insurance and other insurance, health insurance and other insurance also has the effect of cost complementation; for large \& medium-sized life insurance companies, the simultaneous development of ordinary life insurance and participating insurance also has costs complementary effect. 
In general, the instability of the results of each year may be caused by the following reasons: First, the life insurance industry has a long profit cycle, so some small companies with short set-up times may not have a fixed product line, and the 4-year time interval's data may not be able to explain the scale effect and the range effect. The data will be more valuable when the business scale is expanded. The second is the special situation of the Chinese life insurance company. They may not be completely clear about the business scope when preparing for construction., but choose to apply for a full license when the license is relatively easy to apply. This does not explain whether there is range effect.

Table 4 Scale effect and Scope effect for life insurance companies in 2015

Scale effect Large\& Medium

Small

Scope effect

$\begin{array}{lcc}\text { Y1 Y2 } & -96.700 & 0.875 \\ \text { Y1 Y3 } & 331.897 & 2.907 \\ \text { Y1 Y4 } & 9.475 & 3.647 \\ \text { Y2 Y3 } & 103.764 & -1.694 \\ \text { Y2 Y4 } & 3.090 & 1.332 \\ \text { Y3 Y4 } & -9.374 & -3.542\end{array}$

Table 5 Scale effect and Scope effect for life insurance companies in 2014

\begin{tabular}{ccc}
\hline & Large\& Medium & Small \\
Scale effect & 1.113 & 1.409 \\
Scope effect & & \\
Y1 Y2 & -0.233 & -0.278 \\
Y1 Y3 & -0.357 & 0.154 \\
Y1 Y4 & -0.322 & -0.197 \\
Y2 Y3 & 1.079 & 0.549 \\
Y2 Y4 & -0.049 & 0.148 \\
Y3 Y4 & -0.258 & -0.221
\end{tabular}

Table 6 Scale effect and Scope effect for life insurance companies in 2013

$\begin{array}{lcc}\text { Scale effect } & 1.704 & 1.206 \\ \text { Scope effect } & & \\ \text { Y1 Y2 } & -0.628 & 0.824 \\ \text { Y1 Y3 } & 0.307 & -1.088 \\ \text { Y1 Y4 } & 0.985 & 0.494 \\ \text { Y2 Y3 } & 0.174 & -0.692 \\ \text { Y2 Y4 } & -0.506 & -1.001 \\ \text { Y3 Y4 } & -0.292 & 0.261\end{array}$

Table 7 Scale effect and Scope effect for life insurance companies in 2012

$\begin{array}{ccc}\text { Scale effect } & \text { Large\& Medium } & \text { Small } \\ \text { Scope effect } & 1.251 & 1.223 \\ \text { Y1 Y2 } & & \\ \text { Y1 Y3 } & 2.273 & 0.459 \\ \text { Y1 Y4 } & -1.493 & -1.069 \\ \text { Y2 Y3 } & 0.295 & -0.849 \\ \text { Y2 Y4 } & 0.623 & -0.365 \\ \text { Y3 Y4 } & -1.022 & -0.747 \\ & 1.777 & 1.742\end{array}$




\section{SUMMARY}

This paper uses the Translog model combined with the 2012-2015 data to measure the scale effect and range effect of China's life insurance industry. Large \& medium-sized life insurance companies and small life insurance companies are distinguished by whether the asset size reaches 20 billion yuan (20 billion in 2014, 15 billion in 2013, and 10 billion in 2012). The model results show that large \$ medium-sized life insurance companies and small life insurance companies have economies of scale. From the results of the 2015 model, ordinary life insurance and health insurance, health insurance and other insurance have the effect of complementary costs. Therefore, the life insurance company also carries out general insurance and health insurance at the same time in the premium competition. For small life insurance companies, the simultaneous development of participating insurance and other insurance, health insurance and other insurance also has the effect of cost complementation; for large and medium-sized life companies, the simultaneous development of ordinary life insurance and participating insurance is also cost-complementary. effect. Therefore, life insurance companies should strengthen product and service innovation and design products that better meet market needs.

\section{Reference}

Grace M F, Timme S G. An examination of cost economies in the United States life insurance industry[J]. Journal of Risk and Insurance, 1992: 72-103.

Allen, R. F. Cross-sectional estimates of cost economies in stock property-liability companies [J]. The Review of Economics and Statistics. 1974, 56(1): 100-103

Baumol, W. J., Panzar, J. C. and Willig, R. D. (1982), Contestable markets and the theory of industry structure [M]. New York, Harcourt Brace Jovanowitch, Inc.

Benston, G. J. Economies of scale of financial institutions [J]. Journal of Money, Credit and Banking. 1972, 4(2): $312-41$.

Berger, Allen N,David Cummins, Mary A. Weiss and Hongmin Zi, 1999, Conglomeration versus strategic focus: evidence from the insurance industry[J]. Journal of Financial Intermediation (5): 133-152.

Cho, D. Some evidence of scale economies in worker's compensation insurance [J]. Journal of Risk and Insurance. 1988, 55(2): 324-330.

Cummins, J. D. Economies of scale in independent insurance agencies [J]. Journal of risk and Insurance. 1977, 44(4): 539-553

Doherty, N. A. The measurement of output and economies of scale in property and liability insurance [J]. Journal of Risk and Insurance. 1981, 48(3): 390-402

Hammond, J. D., Melander, E. R. \& Shilling, N. Economies of scale in the property and liability insurance industry [J]. The Journal of Risk and Insurance. 1971, 38(2): 181-191

Johnson, J. E., Flanigan, G. B. \& Weisbart, S. N. Return to scale in the property and liability insurance industry", The Journal of Risk and Insurance. 1982, 48(1): 18-46.

Joskow, P. W. Cartels, Competition and regulation in the property-liability insurance industry [J]. The Bell Journal of Economics. 1973, 4: 375-427.

Kim, M. Y. Economies of scale and scope in multiproduct financial institutions: Further evidence from credit unions [J]. Journal of Money, Credit and Banking. 1986, 18, (220-226).

Meador,Joseph W.,Harley E Ryan,Jr and Carolin D Schellhorn,1998, Product focus versus diversification: estimates of X-Efficiency for the U.S. life insurance industry[J]. Working paper,Boston: Northeastern University,MA

Miller, M. Debt and taxes [J]. Journal of Finance. 1977, 32(2): 261-275.

Murray, J. D. \& White, R. W. Economies of scale and economies of scope in multiproduct financial institutions: A study of British Columbia credit unions [J]. Journal of Finance. 1983, 38: 887-901.

Panzar, J. C. \& Willig, R. O. Economies of scope [J]. American Economic Review. 1981, 71: 262-272.

Panzar, J. C. \& Willig, R. D. Economies of scale in multi-output production [J]. Quarterly Journal of Economics. 1977, 91(3): 481-93. 
Praetz, P. A Note on economies of scale in the United Kingdom property-liability insurance industry [J]. The Journal of Risk and Insurance. 1985, 52(2): 315-320

Sealey, C. W. \& Lindley, J. T. Inputs, outputs, and a theory of production and cost at depository financial institutions [J]. Journal of Finance. 1977, 32(4): 1251-66

Skogh, G. Returns to scale in the Swedish property-liability insurance industry [J]. The Journal of Risk and Insurance. 1982, 49(2): 218-228.

Suret, J. M. Scale and scope economies in the Canadian property and casualty insurance industry [J]. The Geneva Papers on Risk and Insurance. Issues and Practice, Assessing the Performances of the Insurance Industry (I). 1991, 16(59): 236-256.

Huang. Scope economy of China's insurance industry[J]. The Journal of Quantitative \& Technical Economics. 1907 (11): 86-95

$\mathrm{Hu}, \mathrm{Su}$. Does China's property insurance industry have scope economy [J]. Macroeconomics. 2013(6):41-53

Wang, Lu. Scale and Scope Economies in Chinese Property and Liability Insurance Industry [J].Insurance Studies. 2016, (12): 15-24. 